\title{
A Survey on Performance Evaluation of Non- Realistic Mobility Models with Different Routing Protocols on MANET
}

\author{
Manisha Israni \\ Department of Computer Science, \\ Pt. Ravishankar Shukla \\ University, \\ Raipur Chhattisgarh, \\ 492010, India
}

\author{
V.K. Patle \\ Department of Computer Science, \\ Pt. Ravishankar Shukla \\ University, \\ Raipur Chhattisgarh, \\ 492010, India
}

\author{
Sanjay Kumar \\ Department of Computer Science, \\ Pt. Ravishankar Shukla \\ University, \\ Raipur Chhattisgarh, \\ 492010, India
}

\begin{abstract}
We are moving from the traditional wired communications to wireless communications. Wireless network consists of several nodes which communicate without any wired channel. MANET (Mobile adhoc network) is one of the types of wireless network. Mobile means moving, infrastructure less and network means communication between nodes. So, "Mobile adhoc networks" are a kind of Dynamic network in which nodes are moving without any centralized structure. Selection of routing protocol and mobility model in Mobile adhoc network is a challenging task due to its dynamic changes in topologies. We discuss in this paper non-realistic mobility models and various routing protocols of adhoc networks. The objective of this review paper, is to determine the performance measures like throughput, packet Packet delay, Routing overhead, effect of speed, no. of packets transmitted, lost, bytes and bit rate of MANET's Routing Dynamic Source Routing (DSR), Ad-hoc On Demand Distance Vector (AODV) and Temporally Ordered Routing Algorithm(TORA) with respect to time / number of nodes. This detailed simulation results illustrate the importance evaluating and implementing routing protocols environment and this also help to researchers in deciding which mobility model is better under which condition.
\end{abstract}

\section{Keywords}

Mobility Models; MANET; Simulation Tools; Routing Protocols; wireless network;

\section{INTRODUCTION}

Now days, life mostly depends on wireless communication system. There are various application and areas where an infrastructure network is almost impossible to have or maintain. In such situations MANET with their selfconfiguring, self- directed and infrastructure less capability, can be used effectively [1]. Such type of networks are called decentralized networks, they don't have any central controller. In order to thoroughly study a mobile adhoc network, it is important to study its key parameters which effect directly to MANET. Parameters such as mobility models and protocols which are the key factors in MANET due to limited wireless transmission range. The mobility model describes the movement pattern of nodes and also describes their acceleration pattern, velocity and location change over time [2].The routing protocol describes the routing paths through the entire network. Since Mobility models and Routing protocols play a vital role in MANET performance. Thus, when evaluating MANET performance, it is important to choose the proper underlying mobility model and routing protocol. Because selection of wrong model may not yield the desired result. For example, it isn't the right way to use Random mobility model to evaluate the network performance where nodes move together, because the movement of nodes in Random way point model is quite different from other mobility models [3]. Apart from this, Nodes which are very dynamic in nature can frequently make and break the routing links causing frequent updation in routing tables. Each time when links update then routing protocol recalculates the routing information and this process consumes more power, time and may generate traffic on the network [4]. With this nature of network, we can say that security of MANETs is another major concern. Due to these issues MANET is never used in its pure form and to make a reliable network access medium is a key requirement, in this way any adhoc network is connected to the wired networks through access points (AP) to minimize the issues related to security of wireless structure [5]. Although adhoc network has great potential to work with the situation where infrastructure is not available or internet access points are not a key requirement. Like military or disaster application or nodes which only want to communicate each other etc. [6] This survey paper is structure as follows: Section II describes about mobility models their types and performance in MANET, Section III describes about Routing protocols and its types, Section IV discuss about simulation tools that are mainly used for Manet to study about performance of different mobility model and protocols, Section $\mathrm{V}$ focuses on the work that has already done in this field, Section VI highlights the performance of mobility models over different protocols as well as various performance parameters, Section VII investigates about the challenging factors of mobility of nodes and Section VIII conclude the paper and propose future work.

\section{MOBILITY MODEL}

Mobility models are used to simulate and evaluate the performance of mobile wireless systems and the algorithms and protocols at the basis of them. [7] There are two types of mobility models used in the simulation of networks: Realistic and nonrealistic models. Realistic are those mobility patterns that are observed in real life systems. It is also known as group/traces model. They provide accurate information when they involve a large number of nodes and an appropriately long observation time. However, new network environments like ad hoc networks are not easily modeled if traces have not yet been created. In this type of application it is necessary to use nonrealistic models. Generally known as Random 
mobility models .These models attempt to realistically represent the behaviors of MNs without the use of traces.[8]. In this paper, we have used routing protocols from reactive, proactive as well as hybrid categories to make comparison and the performance of routing protocols is observed in nonrealistic mobility model.

\subsection{Realistic Mobility Model}

Unlike Nonrealistic models, in realistic models some limitations are imposed on node movement. The limitations may be due to environmental obstacles, such as buildings, or to the rules made for node movement such as moving in predefined pathways. The rules are made to make node movement more similar to real nodes. [9].

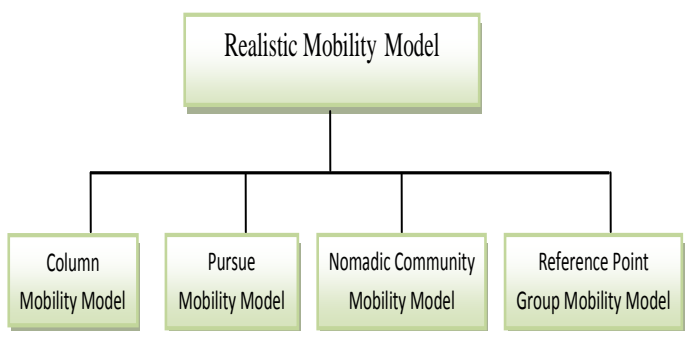

Fig.1 Hierarchy of Realistic Mobility Model

\subsubsection{Column Mobility Model}

This model represents a set of MNs that have formed a line and are uniformly moving forward in a particular direction. For example, consider a row of soldiers marching together towards their enemy. Each soldier stands next to his companions while marching in a uniform manner.[10]

This model traces MNs motion by calculating a new_reference_position for an $\mathrm{MN}$ using the equation:

\section{new_reference_position $=$ old_reference_position +} advance_vector

Where, old_reference_position is a static variable indicating the initial location of an MN, advance_vector is a predefined offset, and new_reference_position is the sum of the MNs initial location (old_reference_position) and the offset (advance_vector).

\subsubsection{Pursue Mobility Model}

As the name implies, the Pursue Mobility Model attempts to represent MNs tracking a particular target. For example, this model represents police officers attempting to catch an escaped criminal or a swarm of bees attempting to attack a careless camper who inadvertently disturbed their dwelling.

The Pursue Mobility Model consists of a single equation for the new position of each MN:

new_position $=$ old_position + acceleration (targetold_position) + random_vector

The current position of an $\mathrm{MN}$ combine a random vector and an acceleration function for calculating the next position of the MN. The acceleration function is used to allow only a limited maximum step in each new movement.

The random vector ensures the random motion of each MN.

\subsubsection{Nomadic Community Mobility Model}

Nomadic Community Mobility Model, which is useful for representing both military and agricultural situations. Just as ancient nomadic societies moved from location to location, this model represents groups of MNs that collectively move from one position to another. [11] Within each community or group of Mobile nodes maintain their own personal "spaces" where they move in random ways.

\subsubsection{Reference Point Group Mobility Model}

Reference Point Group Mobility (RPGM) model, which represents a random motion of a group of MNs as well as a random motion of each individual $\mathrm{MN}$ within the group. Path traveled by a logical center decide the movements of MN in group, which may be pre-defined a group motion vector, GM represents this motion of group nodes. The motion of the group center completely characterizes the movement of its corresponding group of $\mathrm{MNs}$, including their velocity. Individual MNs randomly move about their own predefined reference points, whose movements depend on the group movement. [12].

\subsection{Nonrealistic Mobility Model}

This group of models considers node movement completely randomly. Neither environmental factors, such as buildings, nor non-environmental factors like movement rules can limit the node mobility Different Nonrealistic entity mobility models for ad hoc networks are:

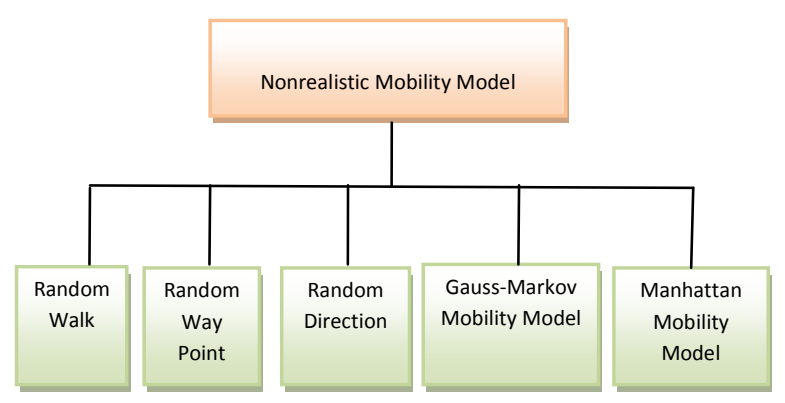

Fig. 2 Hierarchy of Nonrealistic Mobility Model

\subsubsection{Random Waypoint Mobility Model}

A model that includes pause times between changes in destination and speed. The Random Waypoint Model was first proposed by Johnson and Maltz [14]. It is very popular model in modern research .Soon, it became a 'benchmark' mobility model to evaluate the MANET routing protocols because it's simple to use and widely available and can be considered as a foundation of building other mobility model. At every instant, a node randomly chooses a destination and moves towards it with a velocity chosen randomly from a uniform distribution $\left[0, \mathrm{~V} \_\max \right]$, where $\mathrm{V}_{-}$max is the maximum allowable velocity for every mobile node. The node take pause for a duration defined by the 'pause time' parameter while reached at the destination. After this session, it again selects a random destination and repeats the whole process until the simulation ends [15].

\subsubsection{Random Walk Mobility Model}

In this mobility model, a mobile node moves from its current location to a new location by randomly choosing a direction and speed in which to travel. The new speed and direction are both selected from pre-defined ranges, respectively [minspeed, max-speed] and [0,2*pi] respectively. Each movement in the Random Walk Mobility Model occurs in either a constant time interval $t$ or a constant traveled d distance, at the end of this; a new direction and speed are calculated. If the node moves according to the above rules and reaches the boundary of simulation field, the leaving node is send back to the simulation field. [16] This effect is called border effect. The Random Walk model is a memory less mobility process where the information about the previous status is not used for the future status. This implies that the current velocity is independent with its previous velocity and the future velocity is also independent with its current velocity. 


\subsubsection{Random Direction Mobility Model:}

A model that forces MNs to travel to the edge of the simulation area before changing direction and speed. This model was created to overcome the problem i.e. clustering of nodes in one part of the simulation area, that was produced by Random way point model. Random Direction model has many similarities with Random walk model. Selection of random direction to which MNs travel similar to the Random walk mobility model [17]. A mobile node then travels to that particular direction in simulation area. Once the simulation boundary is reached, the mobile node pauses for specified time and selects another angular direction $[0,180]$ and repeat the process.

\subsubsection{Gauss-Markov Mobility Model}

A model that uses one tuning parameter to vary the degree of randomness in the mobility pattern. The Gauss-Markov Mobility Model was first introduced by Liang and has and widely utilized. In this model, the velocity of mobile node is assumed to be correlated over time and modeled as a Gauss-Markov stochastic process. When the node is going to travel beyond the boundaries of the simulation field, the direction of node is forced to flip 180 degree. This way, the nodes are repelled from the boundary of simulation field. In the Gauss-Markov model, to determine the mobility behavior of nodes the temporal dependency plays an important role [18].

\subsubsection{City Section Mobility Model}

A simulation area that represents streets within a city. In the City Mobility Model, the simulation area is a network that represents the section of a city where the ad hoc network exists. Each mobile node starts the simulation at a defined point of some street. A path corresponding to the shortest travel time between the two points is located by the movement algorithm from the current destination to the new destination; with this, there are safe driving characteristics such as a speed limit and a minimum distance allowed between any two mobile nodes. After reaching the destination, the Mobile Node stops for a specific time and then randomly choose another destination (i.e., a point of some street) and the process is repeated again. In this paper we are analyzing about the nonrealistic models.

\section{ROUTING PROTOCOL}

Routing protocols define a set of rules which governs the journey of message packets from source to destination in a network [19].

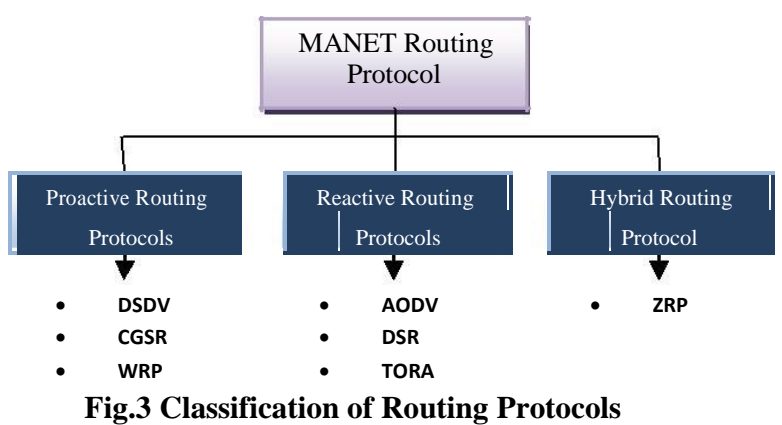

\subsection{Proactive Routing Protocols}

Proactive routing protocol works continuously to evaluate the routes to send packets within the network. So that the route is immediately used whenever packet needs to be forwarded. Proactive routing protocols are also called as table driven routing protocols. Because they maintain one or more routing tables to store information [20].Some of the proactive protocols are-DSDV, CGSR, WRP.

\subsection{Reactive Routing Protocols}

Adhoc Reactive Protocols initiates the routes only on demand. Thus when route is needed to send packets, some sort of global search is initiated to find the shortest path to destination. That is why, Reactive routing protocol is also known as Source-Initiated on demand routing protocol [21].Some of the reactive protocols are-DSR, AODV, TORA.

\subsection{Hybrid Routing Protocol}

This type of protocol is a trade-off between proactive and reactive protocols. Proactive protocols have more overhead and less latency while reactive protocols have less overhead and more latency [19]. Thus a Hybrid protocol is needed to overcome the shortcomings of both proactive and reactive routing protocols. This protocol is a combination of both proactive and reactive routing protocol [21]. Most common example of Hybrid protocol is ZRP.

Define abbreviations and acronyms the first time they are used in the text, even after they have been defined in the abstract. Abbreviations such as IEEE, SI, MKS, CGS, sc, dc, and rms do not have to be defined. Do not use abbreviations in the title or heads unless they are unavoidable.

\section{SIMULATION TOOLS}

Simulations provide a valuable means of compare different protocols and study their performance in terms of efficiency and Robustness. There are many network simulators available for the MANET community [22]. Unfortunately, only $75 \%$ of MANET simulation papers actually mentioned the simulator used in research[23] Fig 4- shows that NS-2 is the most used simulator in MANET research.

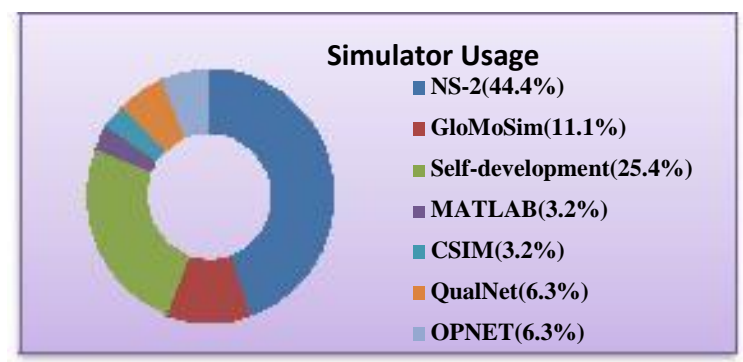

Fig. 4 Simulator used in MANET Simulation Research

There is different simulation tools used for comparison and result analysis-

\subsection{NS2}

NS2 is an open source event-driven simulator design specifically for research in computer communication network. To investigate the performance of network, researchers create simple and an easy-to-use scripting language to configure a network, and observe results generated by NS2 [24].

\subsection{OPNET}

Its provides a graphical editor interface to build models for various network entities from physical layer modulator to application process All these components are modulated in an object-oriented approach which gives intuitive easy mapping to your configured systems. OPNET gives you a flexible and familiar platform to test your new ideas and solutions which low cost.

\subsection{QualNet}

QualNet is a set of comprehensive tools with all the components for custom network modeling and simulation projects. It provide solid library on which to build and experiment new network functionality. Extensive library from 
wired network to cellular network, satellite, mobile ad-hoc networks, for VoIP, telnet, ftp, http etc.

\subsection{GloMoSim}

With GloMoSim we are building scalable simulation environments for wireless scalable simulation environment for wireless network system. Most Network systems are currently built using a layered approach that is similar to the OSI, seven layers network architecture. In GloMoSim, we are trying to build a simulation that will scale to thousands of nodes.

\subsection{OMNET++}

Similar with NS2 and NS3 OMNET++ is also a public-source, component-based simulator which provide graphical user interface (GUI) also. Its primary goal to cover the application area is communication networks. OMNNT++ has generic and flexible architecture which makes it successful in many areas like the IT systems, h/w architectures as well as in business processes.

\section{LITERATURE REVIEW}

We have collected several part of literature in the field of MANET, which highlight existing mobility models as well as protocols in this field and apart from this; we also collected the point of view of researchers and their directions in the future.

The basic of this literature are covered by survey papers [21, 25].these two survey papers gather information about the core behavior of MANET which describes the infrastructure less mobile Adhoc Networks and also conclude that MANET is one of the most important and essential technologies that support future computing scheme[26].

According to E. Alotaibi andB.Mukherjee [27] discussed detail about Routing Protocols and state that protocols should be self healing, self organizing and decentralized.

After that Gang Lu, Gordon Manson and Demetrios Belis [28] deal with detailed research survey into all available mobility models and describe their key features. It also deals with the environments of application, i.e. which mobility model is most suitable in which type of environment

The next part of literature is a mobility model performance comparison by Bhavyesh Divecha, Ajith Abraham, Crina Grosan, Sugata Sanyal [29] which result shows that one model cannot be applied to other model. Hence its consider the mobility of an application while selecting a routing protocol as like DSR gives better performance for high mobility than DSDV.

Muhammad Zaheer Aslam, Dr. Abdur Rashid [30] conclude about the two non realistic mobility model that random way point \& Random Walk both are actually same models apart from the pause time which is Zero in random walk mobility model if we increase the pause time in Random Way Point mobility model, it decrease the mobility and produces different results in both model.

B.A.S Roopa Devi, Dr.J.V.R Murthy, Dr.G.Narasimha[31] also illustrates the experimental results of other non-realistic model in presence of AODV protocol \& some fixed parameters. These results said that performance of the protocols is greatly affected by the mobility models.

\section{REVIEW OF VARIOUS MOBILITY MODELS PERFORMANCE}

\begin{tabular}{|c|c|c|c|}
\hline $\begin{array}{l}\text { Mobility } \\
\text { Models }\end{array}$ & Protocols & $\begin{array}{l}\text { Performance } \\
\text { Metrics }\end{array}$ & Conclusion \\
\hline $\begin{array}{l}\text { - Random } \\
\text { way point } \\
\text { model } \\
\text { - Random } \\
\text { walk model }\end{array}$ & $\begin{array}{l}\text { - AODV } \\
\text { - AOMDV } \\
\text { (multipath } \\
\text { extension of } \\
\text { AODV) }\end{array}$ & $\begin{array}{l}\text { - Throughput } \\
\text { - Node speed } \\
\text { - Average } \\
\text { Delay } \\
\text { - Packet } \\
\text { Send Rate } \\
\text {-Number of } \\
\text { Connection }\end{array}$ & $\begin{array}{l}\text { - Routing } \\
\text { protocol } \\
\text { performance is } \\
\text { better with } \\
\text { Random way } \\
\text { point Model than } \\
\text { that of Random } \\
\text { walk Model.[32] }\end{array}$ \\
\hline $\begin{array}{l}\text { - Random } \\
\text { way point } \\
\text { obility model } \\
\text { - Manhattan } \\
\text { mobility } \\
\text { model } \\
\text { - Reference } \\
\text { Point Group } \\
\text { mobility } \\
\text { model }\end{array}$ & $\begin{array}{l}\text { - DSDV } \\
\text { - AODV }\end{array}$ & $\begin{array}{l}\text { - End to End } \\
\text { delay } \\
\text { - Package } \\
\text { Delivery } \\
\text { Rate } \\
\text { - Packet } \\
\text { Drop } \\
\text { - Throughput }\end{array}$ & $\begin{array}{l}\text { - AODV } \\
\text { performs best } \\
\text { with Group } \\
\text { mobility model. } \\
\text { - DSDV } \\
\text { performs } \\
\text { best with Entity } \\
\text { mobility } \\
\text { model.[33] }\end{array}$ \\
\hline $\begin{array}{l}\text { - Realistic } \\
\text { mobility } \\
\text { model } \\
\text { - Non } \\
\text { Realistic } \\
\text { mobility } \\
\text { model }\end{array}$ & $\begin{array}{l}\text { - DSR } \\
\text { - TORA } \\
\text { - AODV }\end{array}$ & $\begin{array}{l}\text { - Packet } \\
\text { delivery } \\
\text { Ratio } \\
\text { - Throughput } \\
\text { - Average } \\
\text { End to End } \\
\text { Delay } \\
\text { - Route } \\
\text { overhead } \\
\text { - Energy } \\
\text { Consumption }\end{array}$ & $\begin{array}{l}\text { - AODV has best } \\
\text { all round } \\
\text { performance. } \\
\text { - DSR is suitable } \\
\text { for networks with } \\
\text { moderate } \\
\text { mobility Rate. } \\
\text { - TORA suitable } \\
\text { for large mobile } \\
\text { adhoc networks } \\
\text { [34]. }\end{array}$ \\
\hline $\begin{array}{l}\text {-Random } \\
\text { way Point } \\
\text { model }\end{array}$ & $\begin{array}{l}\text { - AODV } \\
\text { - DSDV } \\
\text { - DSR } \\
\text { - OLSR }\end{array}$ & $\begin{array}{l}\text { - Packet } \\
\text { Delivery } \\
\text { Ratio } \\
\text { - Average } \\
\text { end to end } \\
\text { delay } \\
\text { - Routing } \\
\text { Load }\end{array}$ & $\begin{array}{l}\text { - AODV } \\
\text { outperforms all } \\
\text { other routing } \\
\text { protocols.[35] }\end{array}$ \\
\hline $\begin{array}{l}\text {-Random } \\
\text { way point } \\
\text { model } \\
\text {-Random } \\
\text { walk model } \\
\text {-Random } \\
\text { Direction } \\
\text { model }\end{array}$ & $\begin{array}{l}\text {-DSDV } \\
\text {-AODV } \\
\text { - TORA } \\
\text { - DSR }\end{array}$ & $\begin{array}{l}\text { - Speed } \\
\text { - Traffic } \\
\text { - Packet } \\
\text { Delivery } \\
\text { fraction } \\
\text { - Node } \\
\text { Density } \\
\text { - End to End } \\
\text { delay }\end{array}$ & $\begin{array}{l}\text { - AODV perform } \\
\text { best in Random } \\
\text { way point model } \\
\text { and Random } \\
\text { walk model. } \\
\text {-In Random } \\
\text { direction Model, } \\
\text { when network } \\
\text { size is Large, }\end{array}$ \\
\hline
\end{tabular}




\begin{tabular}{|c|c|c|c|}
\hline & & & $\begin{array}{l}\text { DSDV produces } \\
\text { better results than } \\
\text { TORA and } \\
\text { DSR.[36] }\end{array}$ \\
\hline $\begin{array}{l}\text { - Random } \\
\text { way point } \\
\text { Mobility } \\
\text { model } \\
\text { - Manhattan } \\
\text { model } \\
\text { - Freeway } \\
\text { Mobility } \\
\text { Model }\end{array}$ & $\begin{array}{l}\text { - ZRP } \\
\text { - OLSR } \\
\text { - DSDV } \\
\text { - AODV }\end{array}$ & $\begin{array}{l}\text { - Packet } \\
\text { Delivery } \\
\text { Ratio } \\
\text { - Throughput }\end{array}$ & $\begin{array}{l}\text { - DSDV is good } \\
\text { in throughput } \\
\text { ADR ratio than } \\
\text { AODV and ZRP. } \\
\text { - OLSR performs } \\
\text { almost similar to } \\
\text { DSDV. [37] }\end{array}$ \\
\hline
\end{tabular}

\section{CHALLENGING FACTOR IN MOBILITY MODEL}

The performance of any Mobile adhoc Network is highly influenced by the mobile patterns of nodes presented in network. In fact, Mobility of nodes is one of the most important factors that determine performance of any wireless network."Disconnection" is the most challenging and primary issue that should be deal effectively to maximize performance [38]. Thus it is important to deal with the factor which determines the performance of any mobility model in MANET, i.e. (I) find out the ways that accurately capture the mobility of nodes. (II) While at the same time, check it that is it practically possible to mathematical analysis or simulation of this situation.

\section{CONCLUSIONS}

In this survey, we have described that both the network topology and the performance of protocols are significantly influenced by the mobility models and environmental factors. There can be many way to classify all the mobility models that are used in MANET. However, we have grouped them into two categories, Realistic and Nonrealistic mobility models to examining all existing mobility models.

The parameters of the performance metrics of mobility that are used for the mobile adhoc network performance analysis are also discussed.

In future, this study can be done to compare protocols performance in realistic mobility models and performance of some other routing protocols can be evaluated over various mobility models.

We can also extends performance be considering other scenarios like other traffic generators, congestion control algorithms, packet interarrival duration etc.

This work is also extends with other simulator tools of ad-hoc network like OMnet++, NS3, OPNET etc. The other progress of regular and continuing approach of future work can be Quality of Services(QoS) issues, reliability check, energy efficiency, multicast protocols and security concern etc.

\section{REFERENCES}

[1] Apurva Sharma, Dr. Gurpreet and Er.Jaswinder Singh," MOBILITY MODELS FOR MANET: MATHEMATICAL PERSPECTIVE," International Journal of Advanced Research in Engineering and Applied Sciences,pp.61-64, ISSN: 2278-6252, Vol. 2 , No. 5 ,May 2013.
[2] Ashish Gupta , Akhilesh Kosta and Akhilesh Yadav," A Survey on Node Mobility Models on MANET Routing Protocols," International Journal of Research (IJR),pp.854-858 ,ISSN 2348-6848.Vol-1, Issue-5, June 2014

[3] S Gowrishankar, T G Basavaraju and Subir Kumar Sarkar, "Effect of Random Mobility Models Pattern in Mobile Ad hoc Networks", pp. 160-164, IJCSNS International Journal of Computer Science and Network Security, ISSN: 1738-7906, VOL.7 No.6, June 2007.

[4] Alex Hinds, Michael Ngulube, Shaoying Zhu, and Hussain Al-Aqrabi," A Review of Routing Protocols for Mobile Ad-Hoc Networks (MANET)", International Journal of Information and Education Technology, pp. 15, ISSN: 2010-3689, Vol. 3, No. 1, February 2013.

[5] A. Boukerche et al., "Routing protocols in ad hoc networks: A survey," Computer Networks: The International Journal of Computer and Telecommunications Networking, pp. 3032-3080, EISSN: 2308-9830 (Online) / ISSN: 2410-0595 (Print), vol. 55, no. 13, May 2011.

[6] B. Malarkodi, P. Gopal, and B. Venkataramani, "Performance evaluation of AD-hoc networks with different multicast routing protocols and mobility models," in Proc. of 2009 International Conference on Advances in Recent Technologies in Communication and Computing IEEE, India, pp. 81-84, Oct., 2009.

[7] Sunil Kumar Kaushik,Kavita Chahal,Sukhbir Singh, Sandeep Dhariwa, "Performance Evaluation of Mobile Ad Hoc Networks with Reactive and Proactive Routing Protocols and Mobility Models", International Journal of Computer Applications,pp. 28-35, ISSN: 0975-8887, Vol 54, No.17, September 2012.

[8] R. Manoharan and E. Ilavarasan, "Impact of Mobility On The Performance of Multicast Routing Protocols In MANET", International Journal Of Wireless and Mobile Networks (IJWMN),pp.110-119,ISSN : 0975 - 3834 [Online]: 0975 - 4679[Print], Vol 2, No.2, May 2010.

[9] Mr. Sanchez. "Mobility Models". http://www.disca.upv.es/misan/mobmodel.htm (retrieved on Dec 26, 2014).

[10] V.Vasanthi , Hemalatha.M, "Mobility Scenario of Dissimilar Mobility Models using the DSR Protocol in Ad-hoc Sensor Network-A Survey", Special Issue of International Journal of Computer Applications, on Issues and Challenges in Networking, Intelligence and Computing Technologies -ICNICT, pp.11-19, ISSN:0975-8887, November 2012.

[11] Dalu, S.S. Naskar, M.K. ; Sarkar, C.K. "Implementation of a Topology Control Algorithm for MANETs Using Nomadic Community Mobility Model", Published by: Industrial, E-ISBN : 978-1-4244-2806-9, Publisher: IEEE, 8-10 Dec. 2008.

[12] Bai, Fet al ,IMPORTANT: A Framework to Systematically Analyze the Impact of Mobility on Performance of Routing Protocols for Ad Hoc Networks .Available at www.ElsevlerComputerScience.com ,Powered by Science@Direct,Ad Hoc Networks,(2003) 383-403, INFOCOM, 2003. 
[13] X. Hong, M. Gerla, G. Pei, and C. Chiang. "A Group Mobility Model for Ad Hoc Wireless Networks" ACM International Workshop on Modeling and Simulation of Wireless and Mobile Systems (MSWiM'99), August 1999.

[14] J. Broch, D. A. Maltz, D. B. Johnson, Y.-C. Hu, and J. Jetcheva, A performance comparison of multi-hop wireless ad hoc network routing protocols, in Proceedings of the Fourth Annual ACM/IEEE International Conference on Mobile Computing and Networking(Mobicom98), ACM, October 1998.

[15] Upneet Singh Kalra, Mohinder Singh, Shanu Malhotra," Effect of Varying Mobility Model on routing protocols under different scalability and offered load over Wireless ad-hoc network" ,International Journal of Advance Research in Computer Science and Management Studies, pp. 225-235, ISSN: 2321-7782 (Online) Volume 2, Issue 5, May 2014.

[16] M.H. Zayani, V. Gauthier, D. Zeghlache Improving link prediction in intermittently connected wireless networks by considering link and proximity stabilities IEEE Thirteenth International Symposium on "A World of Wireless, Mobile and Multimedia Networks", 2012.

[17] M.K. Jeya Kumar and R.S.Rajesh," Performance Analysis of MANET Routing Protocols in Different Mobility Models", IJCSNS International Journal of Computer Science and Network Security,pp.136141,ISSN : 1816-9503, VOL.9, No.2, February 2009.

[18] B.A.S Roopa Devi1, Dr.J.V.R Murthy2, Dr.G.Narasimha3," Impact of Different Mobility Models on AODV Protocol in MANET with NS-2.35 and Bonnmotion-2.1a", International Journal of Advanced Research in Computer and Communication Engineering, pp. 8227-8231, ISSN (Online) : 2278-1021 ISSN (Print) : 2319-5940 Vol. 3, Issue 10, October 2014

[19] Yasser Kamal Hassan, Mohamed Hashim Abd El-Aziz, and Ahmed Safwat Abd El-Radi, "Performance Evaluation of Mobility Speed over MANET Routing Protocols", International Journal of Network Security , PP.128-138, ISSN :1816-353X (Print), ISSN :1816-3548 (Online), Vol.11, No.3, Nov 2010.

[20] Ashutosh Bharadwaj, Dr. Ajit Singh, "The Performance and Simulative analysis of MANET Routing Protocols with Different Mobility Models", (IJCSIT) International Journal of Computer Science and Information Technologies ,ISSN : 0975-9646, Vol. 5 (2), 2014.

[21] Jagtar Singh , Natasha Dhiman ," A Review Paper on Introduction to Mobile Ad Hoc Networks", International Journal of Latest Trends in Engineering and Technology (IJLTET), pp. 143-149,ISSN: 2278-621X, Vol. 2 Issue 4 July 2013

[22] J. Heidemann , K. Mills , S. Kumar, Expanding confidence in network simulations, IEEE Network: The Magazine of Global Internetworking, v.15 n.5, p.58-63, September 2001 [doi>10.1109/65.953234]

[23] K. Pawlikowski. Do not trust all simulation studies of telecommunications networks, In Proceedings of the 2003 International Conference on Information Networking (ICOIN),pp.899-908,Vol. 2662 ,February, 2003.
[24] Mrs. Saba Siraj, Mr. Ajay Kumar Gupta, Mrs Rinku-Badgujar, "Network Simulation Tools Survey",International Journal of Advanced Research in Computer and Communication Engineering ,pp. 201210, ISSN : $2278-1021$, Vol. 1, Issue 4, June 2012.

[25] R. O. Schmidt and M . A. S.Trentin, "MANETs Routing Protocols Evaluation in a Scenario with High Mobility: MANET Routing Protocols Performance and Behaviour," 2008 IEEE Network Operations and Management Symposium Workshops - NOMS 08, Proceedings of a meeting held 7-11 April 2008, Salvador Da Bahia, Brazil.ISBN: 9781424420674,Publisher: Institute of Electrical and Electronics Engineers (IEEE), April 2008

[26] Jun-Zhao Sun MediaTeam,Machine vision and Media Processing unit, Infotech Oulu,Finland "Mobile adhoc Networking: An Essential Technology for Pervasive Computing" under P.O. Box 4500, FIN-90014 University of Oulu. Proceedings of the 10th IEEE Symposium on Computers and Communications (ISCC), 2005.

[27] E. Alotaibi and B.Mukherjee, "A survey on routing algorithms for wireless Ad -Hoc and mesh networks ," Computer Networks: The International Journal of Computer and Telecommunications Networking, pp 940-965, ISSN:1389-1286, vol. 56, no. 2, October 2011.

[28] Gang Lu, Gordon Manson and Demetrios Belis," Mobility Modeling in Mobile Ad Hoc Networks with Environment-Aware", JOURNAL OF NETWORKS, pp 55-63,ISSN 1796-2056,VOL. 1, NO. 1, MAY 2006.

[29] Bhavyesh Divecha, Ajith Abraham, Crina Grosan, Sugata Sanyal," Impact of Node Mobility on MANET Routing Protocols Models", Journal of Digital Information Management pp. 19-23,ISSN 0972-7272, Volume 5 , Number 1, February 2007.

[30] Muhammad Zaheer Aslam,Dr. Abdur Rashid, "Comparison of Random Waypoint \& Random Walk Mobility Model under DSR, AODV \& DSDV MANET Routing Protocols", International Journal of Advanced Research in Computer Science (IJARCS),pp. 381386, ISSN 0976 - 5697, Volume 2 Issue1 Jan-Feb 2011.

[31] B.A.S Roopa Devi, Dr.J.V.R Murthy, Dr.G.Narasimha " Impact of Different Mobility Models on AODV Protocol in MANET with NS-2.35 and Bonnmotion-2.1a", International Journal of Advanced Research in Computer and Communication Engineering,pp. 82278231, ISSN (Online) : 2278-1021 ISSN (Print) : 2319 5940 Vol. 3, Issue 10, October 2014.

[32] V B Kute, Dr. M U Kharat , "Quality of Service Assessment of AOMDV for Random Waypoint and Random Walk Mobility Models”, International Journal of Computer Science and Mobile Computing,pp.199203, ISSN 2320-088X,Vol.3 Issue.1, January 2014.

[33] R. Mohan,C. Rajan , Dr. N. Shanthi, "A Stable Mobility Model Evaluation Strategy for MANET Routing Protocols", International Journal of Advanced Research in Computer Science and Software Engineering,pp. 5865, ISSN: 2277 128X , Volume 2, Issue 12, December 2012. 
[34] L Raja, Dr. S Santhosh Baboo , "Performance Analysis and Simulation of Reactive Routing Protocols (AODV, DSR and TORA) in MANET using NS -2", International Journal of Advance Research in Computer Science and Management Studies,pp. 256-263, ISSN:2327782(Online),Volume 2, Issue 8, August 2014.

[35] Pragya Gupta and Sudha Gupta, "Performance Evaluation of MANET Routing Protocols in Random Waypoint Mobility Model" , International Journal of Computer Applications, International Conference and Workshop on Emerging Trends in Technology,pp.2530,ISSN : $0975-8887,2013$.

[36] M.K.Jeya Kumar and R.S.Rajesh, "Performance Analysis of MANET Routing Protocols in Different Mobility Models", IJCSNS International Journal of
Computer Science and Network Security, pp. 23-29, ISSN : 1738-7906, VOL.9 No.2, February 2009.

[37] Upneet Singh Kalra, Mohinder Singh, Shanu Malhotra, "Effect of Varying Mobility Model on routing protocols under different scalability and offered load over Wireless ad-hoc network", International Journal of Advance Research in Computer Science and Management Studies, ISSN: 2321-7782 (Online), Volume 2, Issue 5, May 2014.

[38] Towsley, D.," Mobility Models for Wireless Networks: Challenges, Pitfalls, and Successes“, Published in: Principles of Advanced and Distributed Simulation, 2008. PADS '08. 22nd Workshop on, ISSN: 1087-4097, ISBN: 978-0-7695-3159-5, Publisher: IEEE, June 2008. 